\title{
A Pragmatic Approach to Evasions at the Press Conferences of the Chinese Ministry of Foreign Affairs
}

\author{
Feifei Zhang \\ Tiangong University, Tianjin, China \\ Email: 707326859@qq.com
}

How to cite this paper: Zhang, F.F. (2021) A Pragmatic Approach to Evasions at the Press Conferences of the Chinese Ministry of Foreign Affairs. Open Access Library Journal, 8: e7892.

https://doi.org/10.4236/oalib.1107892

Received: August 25, 2021

Accepted: September 23, 2021

Published: September 26, 2021

Copyright () 2021 by author(s) and Open Access Library Inc.

This work is licensed under the Creative Commons Attribution International License (CC BY 4.0).

http://creativecommons.org/licenses/by/4.0/

\section{(c) (i) Open Access}

\begin{abstract}
The paper focuses on evasions at the press conferences of the Chinese Ministry of Foreign Affairs and aims at providing a linguistic explanation for the existence and strategies of those evasions within the framework of the Cooperative Principle and the Relevance Theory. The author collected 229 questions and answers from seventeen press conferences in May, 2021. Based on the analysis of the data, nine evasion strategies are recognized. And three typical evasion strategies are analyzed by three examples. The results show that Chinese spokespeople tend to use covert and overt evasions to save country's face and safeguard the national interests. And the cooperation between the spokesperson and the questioning journalist is limited, which gives rise to evasive answers.
\end{abstract}

\section{Subject Areas}

Pragmatic Linguistics

\section{Keywords}

Evasion, Cooperative Principle, Relevance Theory, Press Conference

\section{Introduction}

The press conference is an important channel for the government to release official information. In the conference, journalists from all over the world attach great importance to "seek information". When answering sharp or sensitive questions, government spokesmen not only want to safeguard national interests, but also want to maintain the "friendship" with journalists, so they often adopt implicit or evasive strategies.

Since evasion is associated with equivocation and ambiguity, scholars usually 
take evasive answers as strategies of ambiguous communication and study its effects on communication. The representative ones are the functional view proposed by Bull and Mayer (1993) [1] and the semantic structure view proposed by Galasinski (2000) [2]. Although there are lots of studies on evasion (Bavelas et al., 1988 [3]; Bull, 1994 [4], 1998 [5]; Clayman, 1993 [6]; Bull \& Mayer, 1993 [1], etc.), most of them analyze it from the perspective of psychology rather than linguistics. In particular, evasion in context of Chinese press conferences has not received enough attention.

Different dimensions from psychology, linguistics, cultural backgrounds, and national interests and so on are taken responsibility for the choice of different answer types. In the paper, Edward T. Hall's theory of high-context culture, Bavelas et al's theory of avoidance-avoidance conflict and Brown \& Levinson's face-saving theory are used to explain it. In addition, the paper applies Grice's conversational cooperation principle and Sperber \& Wilson's relevance theory to make a pragmatic analysis of evasive answers in press conferences of the Chinese Ministry of Foreign Affairs.

The paper first introduces the theoretical frameworks and discusses definitions of evasion strategies. Then data and methodology are given. In the discussion section, three examples of evasion of strategies are analyzed through dialogues. In the last part, reasons behind the evasion are explained and conclusions are drawn. It tries to answer the following questions: 1) Does evasion occur frequently in the press conferences we have collected? 2) What evasive strategies are divided into? 3) What are the reasons for adopting the evasive strategies?

\section{Theoretical Frameworks}

\subsection{Grace's Cooperative Principle}

According to Grace, "there is a set of over-arching assumptions guiding the conduct of conversation. These arise, it seems, from basic rational considerations and may be formulated as guidelines for the efficient and effective use of language in conversation to further cooperative ends" (Levinson, 2001: p. 101) [7]. Based on that, he proposed cooperative principle, which says "Make your conversational contribution such as is required, the stage at which it occurs, by the acceptance purpose or direction of the talk exchange in which you are engaged". And it includes four maxims: the maxim of quality, the maxim of quantity, the maxim of relation and the maxim of manner.

While conversation participants should observe the CP, they do not always observe maxims strictly. So, he discussed four situations of violating the $\mathrm{CP}$, that is, unostentatiously violating, opting out, clash, suspending a maxim and flouting. For various reasons these maxims are often violated, or "flouted". Most of these violations give rise to what Grice calls "conversational implicature".

\subsection{Sperber and Wilson's Relevance Theory}

Relevance theory, proposed by Dan Sperber and Deirdre Wilson, was originally 
inspired by the work of H. Paul Grace. Grace focused more on the intention of the speaker, while Sperber and Wilson also take into consideration of listener's reference, and understand it as the balance between output and input.

By "relevance" it is meant whatever allows the most information to be transmitted in that context on the basis of the least amount of effort required to convey it. The theory regards communication as an ostensive-inferential process, which includes informative intention and communicative intention. As for the press conference concerned in this paper, from the perspective of the spokesman, his communication with the journalists is an ostensive process. He conveys the informative intention and communicative intention to the journalists through his own words. From the perspective of journalists, their communication with the spokespersons is a reasoning process. They obtain contextual effects by combining the spokespersons' information intention with relevant contextual assumptions, so as to understand the spokespersons' communicative intention.

\section{The Definitions and Strategies of Evasion}

Evasion is a mode of speech adopted when the speaker wishes to avoid a direct answer to a question but is unwilling to resort to telling a lie. If you accuse someone of evasion when they have been asked a question, you mean that they are deliberately avoiding giving a clear and direct answer. When someone equivocates, they deliberately use vague language in order to deceive people or to avoid speaking the truth.

There are various definitions about evasion. According to Bavelas et al. (1998) [3], evasion is defined as the "week" statement to avoid clarification. Orr and Bur kins (1976) [8] stressed that evasion may be related to equivocation and ambiguity. And Ng and Bradac (1993) [9] suggested that evasive responses are a form of deliberate irrelevance. To some extent, the pragmatic evasion has different representations, such as approximation, fuzziness, generality, ambiguity, ambivalence in speech communication (Wei Zaijiang, 2006) [10].

The evasion of language has meanings only from the perspective of pragmatics, that is, from the perspective of language use and understanding. The less information the answer provides, the higher the degree of evasion. Bull and Mayer (1993) [1] proposed a relatively systematic classification about the evasive strategies used in political discourse, including the following 11 categories: 1) Ignoring the question; 2) Acknowledging the question without answering it; 3) Questioning the question; 4) Attacking the question; 5) Attacking the interviewer; 6) Refusing the answer; 7) Making a political point; 8) Providing an incomplete answer; 9) Repeating the answer to the previous question; 10) Saying and implying the question has already been answered; 11) Apologizing. We will talk about some of them in the following section.

\section{Research Method}

\subsection{Data Collection}

Data are collected from the website of Ministry of Foreign Affairs of the People's 
Republic of China (https://www.fmprc.gov.cn). The paper analyses regular press conferences of May, 2021. And there are seventeen conferences in May and 229 answered questions raised by reporters, covering major international issues such as the COVID-19 vaccine, the Israeli-Palestinian conflict, border-related issues, the China-U.S. high-level dialogue and so on. The author will select representative samples to analyze the reasons for evasive strategies and the effects it achieved.

\subsection{Data Analysis}

Based on the analysis of the corpus, we distinguished from the direct answers and indirect answers by the amount of the information it provided. Accordingly, we define the former as the answer that provides all the information or the additional information requested by the question, and the latter as the answer that does not provide all the information requested by the question. In this way, the answers can be classified into two main categories as follows (Table 1).

The paper mainly focuses on the indirect answers-overt evasion and covert evasion. And the author found that there was overlap among the eleven types of evasion strategies summarized by Bull and Mayer, such as "repeating the answer to the previous question" and "saying and implying the question has already been answered", "refusing the answer" and "acknowledging the question without answering it". Therefore, the author integrates the eleven strategies into two main types-overt evasion strategies and covert evasion strategies, and found that the former often contains five types and the latter three types. So, strategies are summarized into nine categories and they are commonly used in Chinese Foreign Ministry speeches. As shown in Table 2.

Through the analysis of data, we can see that the first situation accounts for a large number of the total overt evasion strategies, $38.78 \%$. Generally speaking, there are six reasons for respondents to directly refuse to answer the question: do not know the specific situation; the question is not a diplomatic issue; the questions involve interference in other countries' internal affairs; lack of new information; unsure about information, but willing to inquire.

Respondents usually attacking questions for one of the following reasons: the question itself is incorrect; the premise of the question is wrong; a question is an assumption, a question contains the wrong words, etc. And they often challenge a reporter's question by further questioning the question, which is a tactic often

Table 1. The number and percentage of two main question types.

\begin{tabular}{cccc}
\hline Question Types & Detailed Types & Number & Percentage \\
\hline \multirow{2}{*}{ Direct answer } & $\begin{array}{c}\text { Full answer } \\
\text { Additional information }\end{array}$ & 180 & $78.6 \%$ \\
\hline \multirow{2}{*}{ Indirect answer } & $\begin{array}{l}\text { Overt evasion } \\
\text { Covert evasion }\end{array}$ & 49 & $21.4 \%$ \\
& Total & 229 & $100 \%$ \\
\hline
\end{tabular}


Table 2. Detailed division of evasion strategies.

\begin{tabular}{|c|c|c|c|c|}
\hline $\begin{array}{l}\text { Evasion } \\
\text { Strategies }\end{array}$ & $\mathrm{S} / \mathrm{N}$ & Detailed Evasion Types & Number & Percentage \\
\hline \multirow{6}{*}{$\begin{array}{l}\text { Overt Evasion } \\
\text { Strategies }\end{array}$} & 1 & $\begin{array}{l}\text { acknowledge the question without } \\
\text { answering it (refuse answering) }\end{array}$ & 19 & $38.78 \%$ \\
\hline & 2 & question and attack the question & 6 & $12.24 \%$ \\
\hline & 3 & $\begin{array}{l}\text { say the question has already } \\
\text { been answered }\end{array}$ & 5 & $10.20 \%$ \\
\hline & 4 & apologize & 0 & 0 \\
\hline & 5 & attack the journalist & 4 & $8.16 \%$ \\
\hline & & Total & 34 & $69.39 \%$ \\
\hline \multirow{5}{*}{$\begin{array}{l}\text { Covert Evasion } \\
\text { Strategies }\end{array}$} & 6 & make a political point & 6 & $12.24 \%$ \\
\hline & 7 & provide an incomplete answer & 3 & $6.12 \%$ \\
\hline & 8 & ignore the question & 3 & $6.12 \%$ \\
\hline & 9 & $\begin{array}{l}\text { repeat the answer to the previous } \\
\text { question }\end{array}$ & 3 & $6.12 \%$ \\
\hline & & Total & 15 & $30.61 \%$ \\
\hline
\end{tabular}

used in "multiple rounds of questions" (Dou Weilin \& Zhang Xiaoying, 2008) [11].

In covert evasion strategies, showing the political stand is the most used strategy, accounting for $12.24 \%$. Because country's interests are higher than everything and they should be placed into priority.

\section{Discussion}

The section will discuss three typical evasive strategies by giving three examples of dialogues between the China's Foreign Ministry spokesperson and the journalists from different news agencies.

Example 1: Foreign Ministry Spokesperson Hua Chunying's Regular Press Conference on May 14, 2021.

Strategy 1: Acknowledging the question without answering it.

Bloomberg: The Nikkei newspaper reported that China and ASEAN plan face-to-face talks in June. Can you confirm that? And also there was a report that Japanese defense minister would meet with the Chinese defense minister at the Shangri-La Dialogue in Singapore. Can you confirm that too? Thank you.

Hua Chunying: On your first question, I don't have any specific information. But as I said just now, we will hold the China-ASEAN Senior Officials' Consultation on May 18. Since this year marks the 30th anniversary of the establishment of dialogue relations between China and ASEAN, the two sides are in close communication.

As for the second question you mentioned, I would suggest that you go directly to the Ministry of National Defense. 
The spokesman first indicated that she had received and understood the reporter's question, that is, she had grasped the reporter's information intention and communicative intention. However, as the spokesperson has no specific information to provide or is not authorized to release the information requested by journalists, it is impossible to give a full answer. Under such circumstances, the spokesman still wanted to follow the principle of cooperation and provide relevant replies as much as possible. So, she provided the information she knew, that is China and ASEAN are in close communication, and the relevant departments, such as the agricultural ministry, the defense department and the commercial sector, could offer relevant information. In the way, it creates as much contextual effect as possible. From the perspective of cooperation principle, the response of the spokesperson undoubtedly violates the maxim of manner, but this violation leads to a conversational implication, that is, "I am not authorized to provide information requested by you", which is exactly the communicative intention of the spokesperson. At the end of the answer, the speaker suggested that the reporter should seek information from the Ministry of National Defense, which also alleviated the reporter's processing efforts to some extent. In short, the strategy of "Acknowledging the question without answering it" gives as much relevant information as possible in the context of Example 1.

Example 2: Foreign Ministry Spokesperson Zhao Lijian's Regular Press Conference on May 17, 2021.

Strategy 6: Making a political point.

South China Morning Post: Foreign Minister Wang Yi said during his remarks at the UN Security Council that China welcomes representatives from Palestine and Israel to come to China for direct negotiations. Has China invited the two sides already or does it have any plan to do so?

Zhao Lijian: China always holds dear to heart the Middle-East peace process and has been promoting peace talks in its own way. We have stayed in communication with all parties to implement State Councilor Wang Yi's above-mentioned proposals to advance the peace talks process between Palestine and Israel and the full and just settlement of the Palestinian question as soon as possible.

By clarifying China's political position, that is, China is always committed to the Middle East peace and has always handled the issues in its own way. Journalist's processing effort to interpret the language is obviously larger than understand a "yes" or "no" answer, but in this context, contextual effect produced by political position is higher than that of a direct answer. On the one hand, by violating the maxim of manner, a strong implication was produces, that is, China will deal with the issue in its own way rather than the way that journalist refers to, which is fully satisfied the informative intention of the journalist. On the other hand, the speaker also conveys a strong emotion, which carries the speaker's communicative intention. In the latter part of the answer, while the speaker's redundant official position violates the maxim of quantity, it triggered another implication, that is, China's willingness to make efforts to promote the 
Israeli-Palestinian peace talks, which further strengthened the speaker's communicative intention.

Example 3: Foreign Ministry Spokesperson Hua Chunying's Regular Press Conference on May 12, 2021.

Strategy 5: Attacking the journalist.

Reuters: During Ramadan, Reuters viewed dozens of mosques across Xinjiang, including many that were damaged and destroyed. And outside of large cities, mosques were very sensitive places to visit, where we were not allowed to take pictures or have interviews. The foreign ministry and the Xinjiang government have said that they are committed to protecting religious sites in Xinjiang, and the right for people to practice their religions. How is the government ensuring that people can freely and openly practice their religion in Xinjiang, and in cases where mosques have been removed or destroyed, how can the local government ensure there are still places nearby for people to practice their religion?

Hua Chunying: Where are you from?

Journalist: I'm British.

Hua Chunying: You asked a long question in a breath. I would just like to ask, do you know the number of mosques in the UK or the US?

Journalist: No.

Hua Chunying: Let me tell you... So I don't know what is the point in hyping up the issue of mosques in Xinjiang. And before starting the job, have you done your homework? It's always important to do your homework. When making comments, you must make sure you have the facts...

Recently, some anti-China forces from the US and Western countries have been wantonly spreading fallacies like Xinjiang "restricts freedom of religious belief" "deprives ethnic minorities of their right to religious belief" "demolishes mosques by force" "persecutes religious figures" and so on. Disregard of the facts, these groundless fallacies have severely hurt the feelings of people in the Islamic community and Muslims in Xinjiang and have aroused our strong indignation and opposition. Hence grounded on the true situation, the spokesman not only clearly defined the reporter's question as "groundless", but also said that the reporter raised such a question is "unacceptable". Through this strategy of attacking the questioner, the speaker emphasized that allegations hidden in the reporter's questions were totally unacceptable and conveyed a strong sense of dissatisfaction. This strategy, to some extent, transforms the contradiction between the institutions of the two sides into the contradiction between the reporter and the spokesman. It also pushed the contextual effect to the highest point, because the strong dissatisfaction is the most information the spokesman wants to express. So, the outcry in Example 3 should come as no surprise to the journalist present. If, on the other hand, the speaker does not express strong displeasure, that may surprise the reporter and lead to more processing effort on the part of the reporter trying to guess why the speaker did not express strong displeasure. 


\section{The Reasons of Evasion}

1) High context: Chinese people appreciate interpersonal cooperation, and the purpose of communication is to achieve harmonious group relations. One of the characteristics of Edward T. Hall's theory of high-context culture is that information transmission is highly dependent on the cultural and situational context. Thus, people often use indirect language to express meaning, which usually conveys ambiguous and contextual information. When answering questions at press conferences, Chinese spokesmen will place the diplomatic strategy of building a harmonious international environment at an important position in political external publicity. These diplomatic points of view and attitudes are typical characteristics of Chinese high context culture reflected in the field of foreign policy. Therefore, on some issues concerning China's diplomatic and political interests, China sticks to its foreign policy. And this is unquestionable. Pressed by reporters, Chinese spokesmen often parry sharp and unspecified questions with evasive tactics that indicate China's political views.

2) Face Saving: Chinese culture is known for its reticence and emphasis on face. People do not want to lose face, said Bull, and in this way, the spokesmen are no different from us. When faced with a situation in which every answer leads to a loss of face, they prefer not to answer at all. Directly refusing questions or apologizing is a face-threatening act, but implicitly and indirectly answers mitigate the potential damage of a direct confrontation. So, they give incomplete answers to save their own face, the face of the party and the face of the important shareholders.

3) Avoidance-avoidance Conflict (AAC): Bavelas et al. regarded the special situation that conjure evasion as "avoidance-avoidance conflict". In scientific terms, people behave equivocally when they find themselves in a situation if "avoidance-avoidance": when there is absolutely no pleasant way of answering but an answer is required. And he also points out that AAC situation is related to the controversy of the topic, the lack of time to think and the lack of understanding of the topic, and these factors are more common in political discourse to influence people's evasion strategies.

\section{Conclusions}

Pragmatic evasion in verbal communication is a very common phenomenon that deserves further study. It is the language choice made by the speaker driven by strong communicative intention. And it is also used in diplomatic language because diplomacy is the art of putting your feet down without stepping on anybody's toes. Of the two main types of evasion, overt evasion is easy to identify, but covert evasion is not. So, covert evasion deserves more attention.

Combining the cooperation principle and relevance theory to explain the high frequency of evasive strategies in press conferences, the research shows that: 1) Chinese speakers use evasion strategies to answer journalists' questions, but the frequency of using them is relatively rare, accounting for only $21.4 \%$. In most 
cases, they give full and clear explanations to maintain a close relationship with the representatives from different countries and departments. 2) Chinese government spokesmen mostly use overt evasive strategies, accounting for $69.39 \%$. And there are six reasons or situations for respondents to directly refuse to answer the question. 3) The reasons why Chinese spokesmen use evasive strategies can be explained in terms of cultural features such as "face-threatening and saving", "high and low context" and other pragmatic concepts, but language strategies are mostly dependent on the needs of national interests. 4) The press conference of the Ministry of Foreign Affairs is a typical scene of partial withdrawal from cooperation. There is still cooperation between spokesmen and journalists, but the degree is limited.

The success of the press conference has a direct impact on the image and interests of the country. By analyzing the evasion strategies adopted by the spokesman, the paper aims at correcting peoples' misunderstanding and misinterpretation about answers. The evasion answer is not an act of irresponsibility. It is the political and official nature of the press conference that leads to this evasion and stresses polite cooperation. On the other hand, the classification and explanation of the evasion strategies provide a new perspective and have enlightenment on not only the question itself, but also the answering techniques since some questions are "implicational leading" and "preset". There are still some limitations on the classification of the answers' evasion strategies. In order to understand the reasons for the evasion, we must pay enough attention to the proposed questions themselves and conduct in-depth analysis on them.

\section{Acknowledgements}

I would like to express my gratitude to all those who helped me a lot during writing. My deepest gratitude goes first and foremost to Professor Wu Haiying, for her constant encouragement and guidance. She has walked me through all the stages of writing. Without her consistent instruction, this paper could not have reached its present form. Second, my gratitude also goes to all the teachers who have taught me. They are always patient and warm-hearted. Their instructions have given me a lot of inspiration. Last my thanks would go to my beloved family for their loving considerations and great confidence in me. I also owe my sincere gratitude to my friends who gave me their help and time in listening to me and helping me work out my problems during the difficult course of the paper.

\section{Conflicts of Interest}

The author declares no conflicts of interest.

\section{References}

[1] Bull, P. and Mayer, K. (1993) How Not to Answer Questions in Political Interviews. Political Psychology, 14, 651-666. https://doi.org/10.2307/3791379 
[2] Galasinski, D. (2000) The Language of Deception: A Discourse Analytical Study. Sage Publications, Inc., London.

[3] Bavelas, J.B., Black, A., Bryson, L. \& Mullett, J. (1998) Political Equivocation: A Situational Explanation. Journal of Language and Social Psychology, 7, 137-145. https://doi.org/10.1177/0261927X8800700204

[4] Bull, P. (1994) On Identifying Questions, Replies, and Non-Replies in Political interviews. Journal of Language and Social Psychology, 13, 115-131. https://doi.org/10.1177/0261927X94132002

[5] Bull, P. (1998) Equivocation Theory and News Interviews. Journal of Language and Social Psychology, 17, 36-51. https://doi.org/10.1177/0261927X980171002

[6] Clayman, S.E. (1993) Reformulating the Question: A Device for Answering/Not Answering Questions in News Interviews and Press Conferences. Text-Interdisciplinary Journal for the Study of Discourse, 13, 159-188. https://doi.org/10.1515/text.1.1993.13.2.159

[7] Levinson, S.C. (2001) Pragmatics. 11th Edition, Foreign Language Teaching and Research Press, Beijing, China.

[8] Orr, C.J. and Burkins, K.E. (1976) The Endorsement of Evasive Leaders: An Exploratory Study. Central States Speech Journal, 62, 230-239. https://doi.org/10.1080/10510977609367898

[9] Ng, S.H. and Bradac, J.J. (1993) Power in Language. Sage, Thousand Oaks, Newbury Park.

[10] Wei, Z.J. (2006) Pragmatic Vagueness from the Perspective of Diplomatic Language. Foreign Language Research, 2, 45-51.

[11] Dou, W.L. and Zhang, X.Y. (2008) A Comparative Analysis of Evasive Strategies of Chinese and American Government Spokesmen-A Case Study of the North Korean Nuclear Issue. Foreign Language Teaching, 4, 53-57+63. 